\title{
Effective Use of Cement for Modification of Base Course
}

\section{Material}

\author{
Alireza Rezagholilou and Hamid Nikraz \\ Civil Engineering Department, Curtin University, Perth 6100, Australia
}

\begin{abstract}
Cement improves properties of soil materials, such as durability, stiffness, strength and moisture susceptibility. Each of them needs different cement contents that might not be suitable for other properties. Typically, high cement content is desirable for durability, but not for shrinkage and cracking issues on the surface. Thus, improving durability with low cement content while complying with other requirements is an ideal aim, which may be achieved by pozzolanic supplementary products. Pozzolans contribute in hydration reactions and optimise cement consumptions in favour of durable and low shrinkage products. In this paper, the mixes of nano-silica and fly ash are considered to investigate their effect on strength, durability and shrinkage of modified CRB (crushed rock base) material. In the end, the benefits and features of nano-silica as a pozzolanic material will be focused and discussed more for effective cement consumption in soils.
\end{abstract}

Key words: Nano-silica, cement modification, durability, shrinkage.

\section{Introduction}

For flexible pavements, crushed rock aggregates can be used as base course materials. Like other types of soils, this material is susceptible to moisture content fluctuation during the service life of pavements. In WA (Western Australia), thickness increase of CRB (crushed rock base) course materials could not rectify moisture susceptibility of this material [1]. Laboratory investigation by Butkus and Lee Goh [2] showed that CRB material loses its MR (resilient modulus) for about $20 \%$ to $25 \%$ for every $1 \%$ rise in moisture content. Thus, cement modification was considered as one of the options for treating of this material, while avoiding fatigue, in some trial sections of highways in WA [3]. In general, cement modification of soils increases the strength or resilient modulus for about $70 \%$ to $500 \%$ of untreated soil [4]. The cement content of the mixtures depends upon required properties, such as MR or UCS (unconfined compressive strength) of material.

Corresponding author: Alireza Rezagholilou, Ph.D., research fields: geotechnics, durability, pavement and nanotechnology.
Typically, it is also considered up to $2 \%$ [5] in Australia for CRB material to avoid fatigue issue. However, it is likely that less than $1 \%$ cement could produce bound material with subsequent fatigue cracks reflected on wearing course [2]. Therefore, the lower range of cement is tried here to minimise shrinkage cracks. However, this idea implicitly is opposite to the durability requirement of this material which needs often more than $4 \%$ cement content in similar materials [6]. Hence, effective using of hydration products was targeted here by means of pozzolanic products.

Pozzolanic materials, such as fly ash and nano-silica, might adjust different cement requirements of this material. This point needs can be investigated further by nano-silica effects on shrinkage and durability of cemented soils.

\section{Cement Hydration}

Chemical reactions below always define the cement hydration reactions:

$$
\begin{gathered}
2\left(3 \mathrm{CaO} \cdot \mathrm{SiO}_{2}\right)+6 \mathrm{H}_{2} \mathrm{O}= \\
3 \mathrm{CaO} \cdot 2 \mathrm{SiO}_{2} \cdot 3 \mathrm{H}_{2} \mathrm{O}+3 \mathrm{Ca}(\mathrm{OH})_{2}
\end{gathered}
$$




$$
\begin{array}{r}
2\left(2 \mathrm{CaO}_{2} \cdot \mathrm{SiO}_{2}\right)+4 \mathrm{H}_{2} \mathrm{O}= \\
3 \mathrm{CaO} \cdot 2 \mathrm{SiO}_{2} \cdot 3 \mathrm{H}_{2} \mathrm{O}+\mathrm{Ca}(\mathrm{OH})_{2}
\end{array}
$$

Among other cement compounds, only calcium silicates contribute to strength. The initial strengths (first seven days) relate to tricalcium silicate $\left(\mathrm{C}_{3} \mathrm{~S}\right)$ and the later strengths are affected by dicalcium silicate $\left(\mathrm{C}_{2} \mathrm{~S}\right)$, which reacts more slowly. Each of these compounds generates calcium hydroxide, which can enter into extra reactions with siliceous pozzolanic materials.

As indicated above, main reactions end to production of silica gel (CSH), which binds soil particles together. By hardening of soil and cement mixture, the material gets rigidity that has a significant influence on durability and strength.

However, cement compounds or hydration reactions require water to be activated. Water has key roles in all the characteristics of soil cement mixtures in terms of its strength, porosity and durability. The water content in optimum moisture content is often higher than the amount necessary for hydration reactions which are always determined by compaction test. Czernin [7] suggested that hydration reactions can be completed theoretically by $w / c$ (water/cement) ratio of around 0.25 but cemented mixtures, like concrete, usually require more water to be workable. This extra water leaves a porous structure including different pore sizes during the drying stage.

Heat generated voids during gradual drying generate suction pressures which lead to shrinkage cracks in hardened cement paste finally. Based on International Union of Pure and Applied Chemistry [8], the pore structure is classified as:

- micropores: less than $25 \eta \mathrm{m}$;

- mesopores: between $25 \eta \mathrm{m}$ and $500 \mathrm{\eta m}$;

- macropores: between $500 \eta \mathrm{m}$ and $50 \mu \mathrm{m}$.

The structure and volume of pores directly influence the durability and shrinkage of cement treated soils by diffusion of vapour or dissipation of water in voids. The size distribution of pores in cement pastes can be determined by either nitrogen or mercury porosimetry tests. Typical results of these tests are shown in Fig. 1.

According to Fig. 1, in the early stage of hydration, the tendency of hydration reactions is to produce a wide range of pores from macro to micro sizes in the mixture. This situation changes as the majority of paste in volume is filled with pores finer than $100 \mathrm{\eta m}$ in diameter after $60 \%$ hydration.

Furthermore, the volumetric proportion of micro to meso size pores also alters by hydration progress; Micropores volume seems to be higher than micropores at the final stages of hydration.

\section{Shrinkage}

Shrinkage cracks as surficial defects of cemented layers. They are pathways of surface waters which lead to weakened or weathered chemical bonds. Abundance and distribution of cracks are functions of the multiple things, such as cement content, moisture content, density, compaction, curing, amount and type of fine particles.

George [9] claimed that cracks up to $2.5 \mathrm{~mm}$ in width could be tolerable for coarse grain soils with the strength of less than 3.1 MPa. Accordingly, fine grain soils can be considered desirable for cracks up to $1.5-\mathrm{mm}$ width, whereas their strength is not more than $2.07 \mathrm{MPa}$.

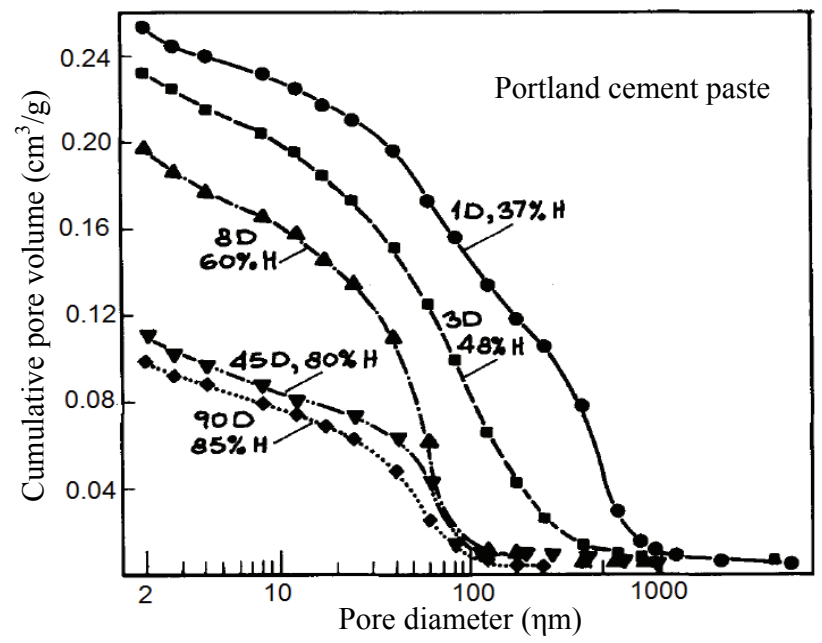

Fig. 1 Cumulative pore-size distribution curve ( $\eta \mathrm{m})$ for cement paste at varying degrees of hydration [10]. 
Unlike concrete, control of cracks in soil cement works is not usual by reinforcement or joints. The best way is to amend mix design and to limit compression or indirectly tensile strengths for lowering bounding characteristics of cemented soils. In this case, aggregates can slide over each other in flexible pavements.

A standard shrinkage test method, especially for soil cement mixtures, is necessary which has not been established yet. As such, the test methods of concrete are applied despite their limitations. In practice, pre-cracking technics by vibratory rollers and before surfacing are also suggested, which diminish stiffness of material for about $40 \%$ and limit further cracks [11].

The other way of shrinkage restriction is to modify the pore distribution of soil cement mixtures. Researches by Bentur [10] on cement paste and Chakrabarti and Kodikara [12] on the fines portion of cement stabilised base material (including crushed basaltic rocks) according to Figs. 2 and 3 have depicted that shrinkage is governed by pores within the range of micropores and mesopores that vary in size between $2.5 \eta \mathrm{m}$ and $30 \mathrm{\eta m}$.

Chakrabarti and Kodikara [12] examined CRB with mercury intrusion tests by using the passings of $0.425-\mathrm{mm}$ sieve. The results in Fig. 2 show that macropores have the least shrinkage or suction effects among other pore sizes.

In other words, it can be inferred that the coarse and neutral fillers do not have a significant contribution to shrinkage.

Bentur [10] tried both of shrinkage and porosimetry tests on the fragments and $12.5-\mathrm{mm}$ cubes of PC (Portland cement) paste samples with water/solids ratio of 0.4. In Fig. 3, total pore volume could not be correlated with drying shrinkage. This is while the well-curved correlation of shrinkage observed with the volume of mesopores with less than $30 \mathrm{\eta m}$.

Both of the findings in pure cement and cement modified crushed rock base material highlight the importance of mesopores in cement pastes in the behaviour of the whole material. These pores can easily be filled with nano-silica particles as a kind of pozzolanic materials.

\section{Durability}

As noted earlier, durability is one of the key design requirements which determines the cement content of soil cement mixtures. In early design guides, durability was the only fundamental property required in the design process. It is normally measured and quantified by the resistance of the material against wet/dry or freeze/thaw cycles. However, in some arid countries, such as Australia, design guides do not emphasize on durability matters and use UCS as an indicative of stiffness.

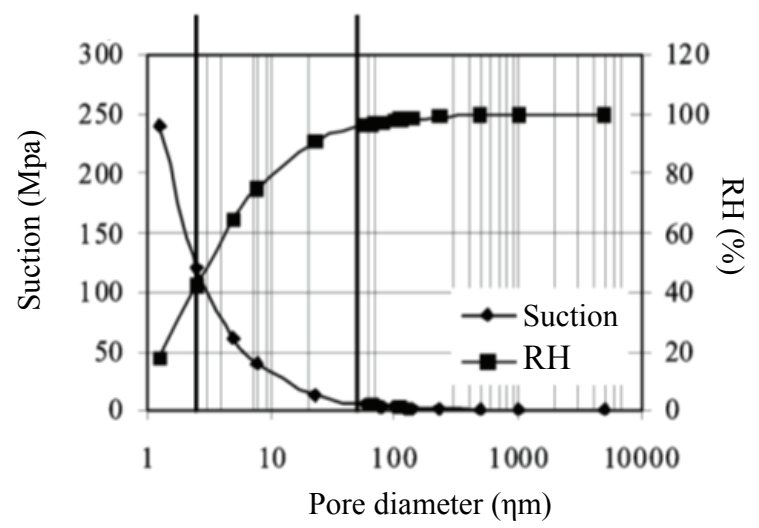

Fig. 2 Pore size distribution versus suction pressure and RH (relative humidity) for cement paste [12].

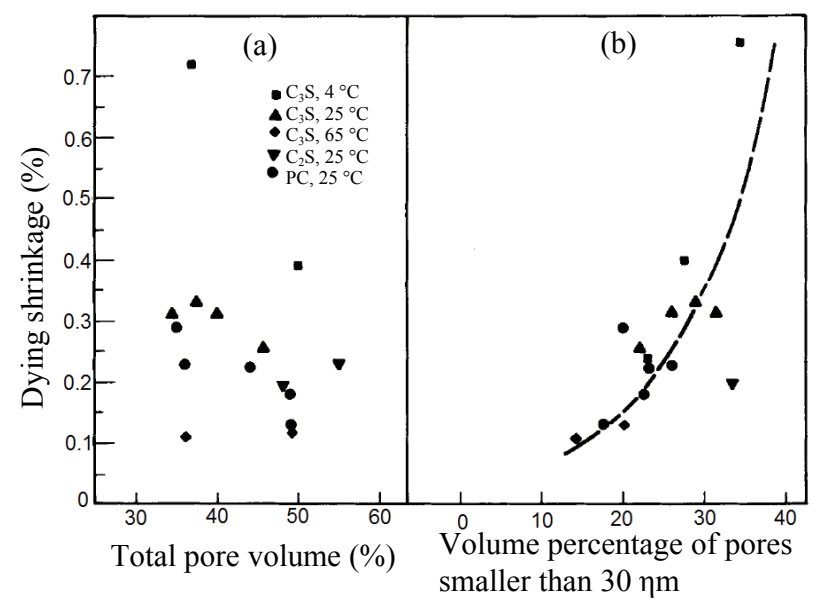

Fig. 3 Relation of shrinkage to: (a) total porosity; (b) volume of pores $\leq \mathbf{0 . 0 3} \boldsymbol{\mu m}$ in diameter [10]. 
Nevertheless, there are different test methods for durability by 12 cycles of wetting and drying, typically according to ASTM D559, and freezing and thawing according to ASTM D560. In fact, these tests try to simulate the severe environmental condition or weathering which depend on the permeability of the material. Pore size distribution and structure can also influence durability, similar to shrinkage.

Same as shrinkage test methods, above tests also have their own constraints regarding test duration and operator susceptibility. Thus, design agencies use UCS as an indirect and index test in durability investigation.

\section{Pozzolanic Additives}

Pozzolanic additives in the cemented materials react with free lime or calcium hydrate to produce more silica gel. The pozzolanic reaction of silica oxides has not been studied, as well as cement hydration reactions, but it can be represented as follows:

$$
3 \mathrm{Ca}(\mathrm{OH})_{2}+2 \mathrm{SiO}_{2}=3 \mathrm{CaO} \cdot 2 \mathrm{SiO}_{2} \cdot 3 \mathrm{H}_{2} \mathrm{O}
$$

Pozzolanic materials are available in various ranges of 100 200 $\mathrm{\eta m}$ for silica fume and 2,000 3,000 $\mathrm{\eta m}$ for pulverised fly ash. Apart from chemical benefits, they can serve as the filler of pore spaces that improve durability and shrinkage difficulties of the cement mixture.

Goldman and Bentur [13] studied silica fume in the cemented materials and showed that filling properties at the micro-level are more significant than the pozzolanic chemical effect. Similarly, Zhang et al. [14] noted better packing state and a decrease of the filling water with the incorporation of nano-silica.

Thus, the idea of using fine pozzolanic material could come up to reduce pore size, porosity and subsequently improves shrinkage, durability and mechanical parameters. As such, it seems that mitigation of shrinkage and durability challenges would be possible by pozzolanic products in nano scale.

\section{Nano Products}

As per ASTM E2456-06 [15], nanotechnology deals with particles with at least one dimension between approximately $1 \sim 100 \quad \eta \mathrm{m}$. In another definition by BSI (British Standards Institution), PAS71 nano particles bring molecular changes to modify macro level characteristics of material.

In concrete technology, nano particles influence strength, durability and construction rate. One of them, as nano-silica, has more than $98 \% \mathrm{SiO}_{2}$ with particle sizes in the range of $10 \sim 30 \eta \mathrm{m}$. This type of nano particle acts similar to pozzolanic additives with higher silica content.

Jo et al. [16] introduced 3\% 12\% nano-silica into cement mortar and summarised its performance as:

- filling the nano-sized pores of the cement paste;

- reacting with free lime $\mathrm{Ca}(\mathrm{OH})_{2}$ and generating additional $\mathrm{CSH}$.

These characteristics of nano-silica may be beneficial for durability and shrinkage issues of soil cement mixtures. They can help stronger bonds essential for durability of material while controlling shrinkage.

Currently, there is limited research regarding nano-silica effects on shrinkage or durability of soil cement mixtures. Thus, this point encouraged authors to undertake below experimental program to evaluate the nano-silica effects on durability and shrinkage of CRB material.

\section{Experimental Program}

The constituents of mixtures in this program were involved CRB material, cement, fly ash and nano-silica. Each of them is explained in the summary below.

\subsection{Properties of Materials}

CRB material was mainly granite and dolerite particles. Its particle size distributions according to Australian Standard AS 1289.3.6.1-2009 has shown in Fig. 4. Graphs conform to the margins indicated in 
Specification 501 by MRWA (Main Roads of Western Australia).

The cement used was typical GP (general purpose) cement supplied in WA. Its particles vary from $2 \mu \mathrm{m}$ to $100 \mu \mathrm{m}$ in diameter.

Fly ash was sourced from the Collie power station, located in the south of WA. It was a fine cream/grey powder with low lime content. About $80 \%$ of these fly ash particles were finer than $45 \mu \mathrm{m}$ as required by ASTM C 618 and about $50 \%$ of particles are less than $11 \mu \mathrm{m}$ in diameter. It has reactive amorphous content $\left(\mathrm{SiO}_{2}\right)$ of $51.8 \%$, and its coarseness supports the idea of using nano silica in filling with the pores up to nano scales in the paste.

The applied nano-silica was Aerosil 200 that meets the ASTM E2456-06 definition for nano particles. Its particles sizes vary from $1 \eta \mathrm{m}$ to $100 \eta \mathrm{m}$. It consists of spherical particles with an average primary particle size of $12 \eta \mathrm{m}$ and with a specific surface area of $200 \mathrm{~m}^{2} / \mathrm{g}$.

\subsection{Mixing Details and Sample Preparation}

In Australia, CRB materials are often modified with $2 \%$ binder [5]. As such two main mixtures of cement and fly ash (by dry weight of aggregate) are considered as B1 and B5 in Table 1.

The cylindrical specimens of each mixture had 28-day strength between 0.7 MPa and 1.5 MPa as indicated in Austroad [17]. In the meantime, 7-day strength of similar samples were less than 1.0 MPa which could comply with the design guideline in WA [18]. Fly ash mainly was to make the less porous material in the accepted range of total binder content.

In next step, each composition was also developed further by adding $0.3 \%, 0.6 \%$ and $0.9 \%$ nano-silica (by dry weight of cement), respectively. Therefore, eight batches from B1 to B8 were considered for another test, as shown in Table 1. B1 and B5 had no nano-silica as control batches for comparison purposes of the other batches.

Before preparation of test samples, it was required to have an OMC (optimum moisture content) and maximum dry unit weight $\left(\gamma_{\text {max }}\right)$ of each batch according to AS 1289.5.1.1 standard test method. Results of various compaction tests showed that the OMC and $\gamma_{\text {max }}$ of batches are nearly $6 \%$ and $23.2 \mathrm{kN} / \mathrm{m}^{3}$, respectively.

During preparation of each mixture for compaction test, nano-silica was added to water separately and completely mixed with water in a shaker. The solution was then added to dry mix of cement, fly ash and aggregates. The blending of each batch continued in a 60-L mixer for $5 \mathrm{~min}$.

This method of blending of mixtures was kept for UCS, wet/dry cycles and shrinkage tests.

\subsection{Unconfined Compressive Strength Test Results}

Double specimens from each batch were prepared and broken according to AS 1141.51-1996 [19] test method. Fig. 5 shows the summary of these tests for

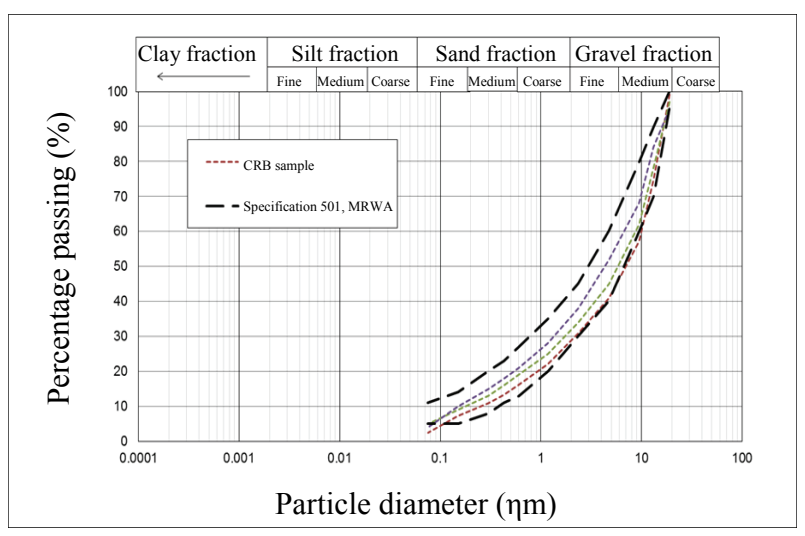

Fig. 4 Particle size distribution of CRB materials.

Table 1 Details of different batches.

\begin{tabular}{lllllllll}
\hline Batch & B1 & B2 & B3 & B4 & B5 & B6 & B7 & B8 \\
\hline Nano content (\%) & 0.0 & 0.3 & 0.6 & 0.9 & 0.0 & 0.3 & 0.6 & 0.9 \\
Cement content (\%) & 0.9 & 0.9 & 0.9 & 0.9 & 0.7 & 0.7 & 0.7 & 0.7 \\
Fly ash content (\%) & 1.1 & 1.1 & 1.1 & 1.1 & 1.3 & 1.3 & 1.3 & 1.3 \\
\hline
\end{tabular}


28-day and wet cured samples.

These figures indicate that addition of nano-silica increases the strength of mixtures steadily. This improvement has a slight rate and uniform trend up to $0.6 \%$ nano content. However, there were no up and down figures by an increment of nano particles.

\subsection{Wet/Dry Cycles Tests Results}

The ASTM standard test method D559-03 [20] was considered to study the durability status of samples with nano-silica. The obtained outcomes, as Figs. 6 and 7, highlight the enhancement of durability by declining of weight losses.

It is also evident that durability of B1 and B5 has improved from more than nearly $40 \%$ to about $30 \%$ or by nano-silica addition. This means that addition of less than $1 \%$ of nano-silica can improve durability for about $25 \%$.

Weight losses indicate considerable improvements compared with original batch B1 and B5, but still could not satisfy the requirements provided by PCA (Portland Cement Association) [21] for less than 14\%.

\subsection{Shrinkage Tests Results}

The aim of this test was to measure the shrinkage of material during drying of CRB modified materials. The test protocol was according to standard method AS 1012.13-1992 [22] for concrete specimens with $75 \mathrm{~mm} \times 75 \mathrm{~mm} \times 280 \mathrm{~mm}$ in size. The maximum size of particles required to be adjusted to include specimen/maximum aggregate size ratio of less than 5 . Thus, the CRB material (over $9.7 \mathrm{~mm}$ sieve size) was separated, removed and replaced by fine aggregates.

Shrinkage of the beam specimens was recorded by a horizontal comparator to measure changes in horizontal plane parallel to compacted layers in practice, as shown in Fig. 7.

There were no observable cracks on the faces of specimens which might be due to the small size of specimens. However, continuous readings of length changes during 28 days can be demonstrated in Fig. 8.
Results might seem to be unsuccessful at first glance while seeing Figs. 9 and 10.

But in both figures, the shrinkage range of nano added material are less than 310 microstrains for coarse material, as suggested by George [9]. This limit is based on PCA's experience from gathered surveying of pavements by different authorities.

Thus, these results are not necessarily far from the purpose of numerous minor cracks instead of few

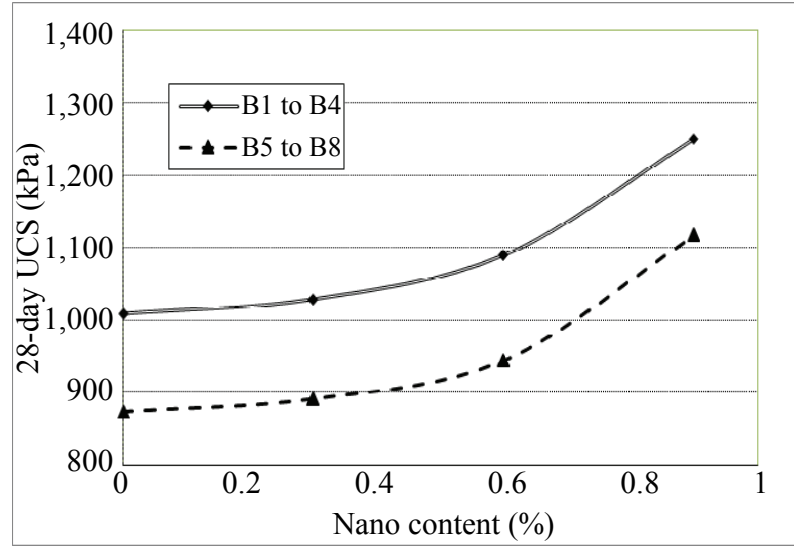

Fig. 5 UCS results for various batches.

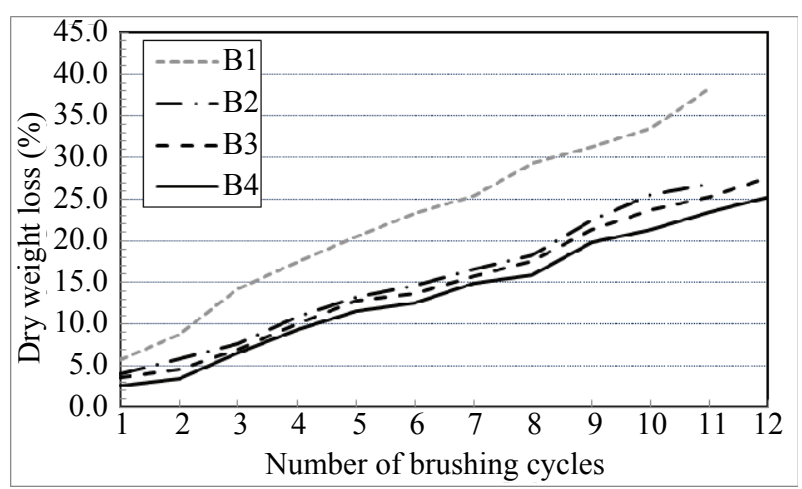

Fig. 6 Wet/dry cycles test results for various batches.

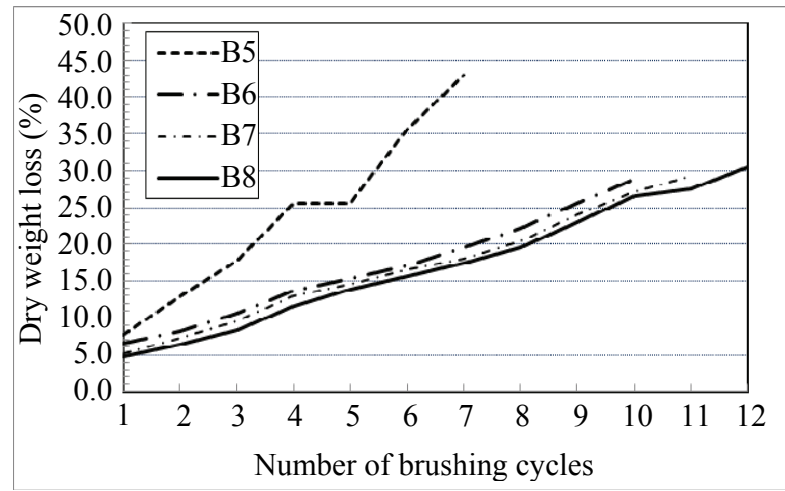

Fig. 7 Wet/dry cycles test results for various batches. 


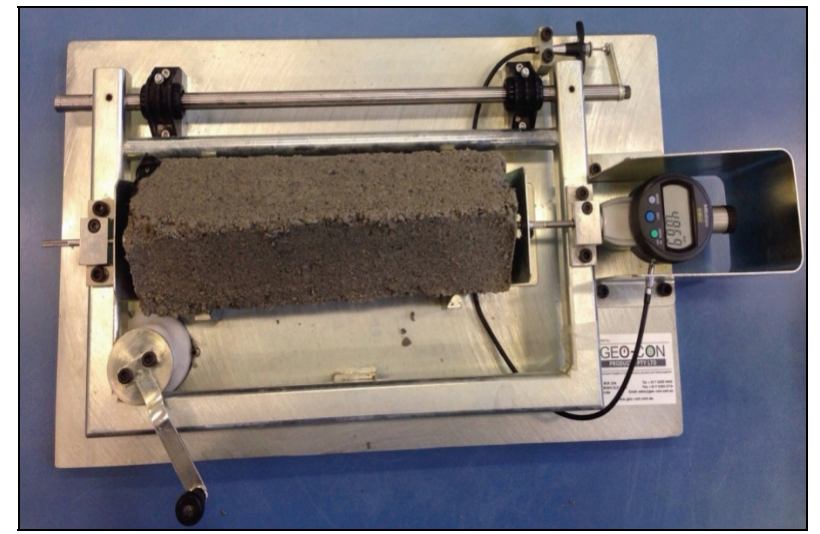

Fig. 8 Horizontal comparator.

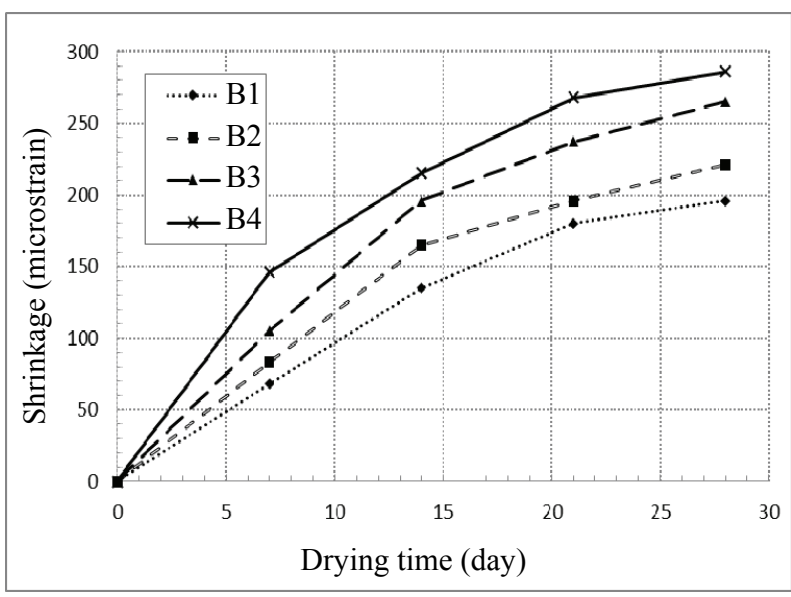

Fig. 9 Shrinkage test results for various batches.

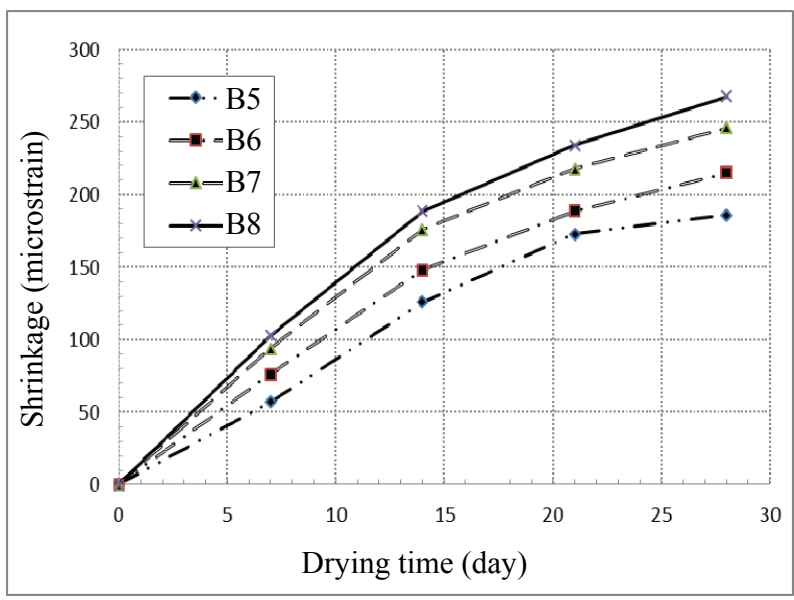

Fig. 10 Shrinkage test results for various batches.

wide cracks. This is to ensure that cracks do not propagate deeply as pathways for water infiltration. Furthermore, debonding of surface layer interfaces become limited by the weakening of base course or subgrade layers.

Authors have assessed the microstructural changes of above-considered mixes in a separate paper. Images obtained from SEM (scanning electron microscopy) indicate more solid and less porous matrix by increasing nano-silica content [23].

\section{Conclusions}

As discussed, mix design of cement modified crushed rock base material require diverse cement contents. Thus, the intention was to use cement efficiently in order to meet both of shrinkage and durability requirements. As such, a broad range of pozzolanic particles from fly ash to nano-silica utilised. Results showed that some of the key properties altered in the direction of more effective soil modification. In the case of CRB material here, nano-silica made the material less permeable, stronger and durable. Although shrinkage in one-dimensional form is increased by nano-silica within the allowable limit, this subject cannot be considered as a reason or rejecting nano-silica. Other tests representing more real condition are necessary to investigate and understand shrinkage cracking patterns in planar mode.

\section{References}

[1] Harris, D., and Lockwood, N. 2009. Reid Highway Base Course Test Sections Construction Details and Performance to December 2008 (94/15 M). Main Roads Western Australia report.

[2] Butkus, F., and Lee Goh, A. 1997. Pavement Moduli Project: A Review of Repeated Load Triaxial Test Results. Materials and pavement technology engineering report, Main Roads Western Australia.

[3] Yeo, Y. S., and Nikraz, H. 2009. "Cement Stabilisation of Road Base Course: A Chronological Development in Western Australia." Australian Geomechanics 44 (3): 57-68.

[4] Little, D. N. 1995. Guidelines for Mixture Design and Thickness Design for Stabilized Bases and Subgrades. College Station: Texas Transportation Institute.

[5] Jameson, G., and De Carteret, R. 2009. Part 4I: Earthworks Materials, Guide to Pavement Technology (978-1-921551-27-7). Sydney: Austroads.

[6] Symons, M., and Poli, D. 1996. "Road Reconstruction Using Cementitious Binders." Presented at National Symposium on the Use of Recycled Materials in 
Engineering Construction, Barton, Australia.

[7] Czernin, W. 1962. Cement Chemistry and Physics for Civil Engineers. 1st ed. New York: Chemical Pub. Co.

[8] International Union of Pure and Applied Chemistry. 1975. Manual of Symbols and Terminology for Physicochemical Quantities and Units-Appendix Ii. Madrid: International Union of Pure and Applied Chemistry.

[9] George, K. 2002. Minimizing Cracking in Cement-Treated Materials for Improved Performance. Skokie: Portland Cement Association.

[10] Bentur, A. 1980. "The Pore Structure of Hydrated Cementitious Compounds of Different Chemical-Composition." Journal of the American Ceramic Society 63 (7-8): 381-6.

[11] Scullion, P. E. T. 2001. "Field Investigation: Pre-cracking of Soil-Cement Bases to Reduce Reflection Cracking." Presented at Annual Meeting of Transportation Research Board, Washington, D.C., USA.

[12] Chakrabarti, S., and Kodikara, J. 2007. "Microstructure and Its Relationship to Some Material Properties of Cementitiously Stabilised Crushed Basaltic Rock.” Road and Transport Research 16 (2): 3-18.

[13] Goldman, A., and Bentur, A. 1994. "Properties of Cementitious Systems Containing Silica Fume or Nonreactive Microfillers." Advanced Cement Based Materials 1 (5): 209-15.

[14] Zhang, C., Wang, A., Tang, M., and Liu, X. 1996. "The
Filling Role of Pozzolanic Material." Cement and Concrete Research 26 (6): 943-7.

[15] Standards Australia. 2012. ASTM E2456-06: Standard Terminology Relating to Nanotechnology. Sydney: Standards Australia.

[16] Jo, B. W., Kim, C. H., and Lim, J. H. 2007. "Characteristics of Cement Mortar with Nano- $\mathrm{SiO}_{2}$ Particles." ACI Materials Journal 104 (4): 404-7.

[17] Austroads. 2006. Guide to Pavement Technology. Part 4D: Stabilised Materials. Sydney: Austroads.

[18] MRWA (Main Roads of Western Australia). 2012. Engineering Road Note 9: Procedure for the Design of Road Pavements. Western Australia: MRWA.

[19] Standards Australia. 1996. Australian Standard AS 1141.51: Methods for Sampling and Testing Aggregates-Unconfined Compressive Strength of Compacted Materials. Sydney: Standards Australia.

[20] Standards Australia. 2003. ASTM D559-03: Standard Test Methods for Wetting and Drying Compacted Soil-Cement Mixtures. Sydney: Standards Australia.

[21] PCA (Portland Cement Association). 1992. Soil-Cement Laboratory Handbook. Illinois: PCA.

[22] Standards Australia. 1992. AS 1012.13: Methods of Testing Concrete. Determination of the Drying Shrinkage of Concrete. Sydney: Standards Australia.

[23] Rezagholilou, A., Nikraz, H., and Paige, G. P. 2015. "Effects of Nano-silica on Cement-Fly Ash Modified Crushed Rocks Base Materials." Nanotechnology and Materials Science 2 (1): 1-6. 